\title{
HLA Allele Associations and V-Beta T-Lymphocyte Expansions in Patients With Psoriasis, Harboring Toxin-Producing Staphylococcus aureus
}

\author{
Rola Ajib, ${ }^{1}$ Lori Janbazian, ${ }^{1}$ Elias Rahal, ${ }^{1}$ Ghassan M. Matar, ${ }^{1}$ \\ Shukrallah Zaynoun, ${ }^{2}$ Abdul-Ghani Kibbi, ${ }^{2}$ and Alexander M. Abdelnoor ${ }^{1}$ \\ ${ }^{1}$ Department of Microbiology and Immunology, Faculty of Medicine, \\ American University of Beirut, Beirut 1107 2020, Lebanon \\ ${ }^{2}$ Department of Dermatology, Faculty of Medicine, American University of Beirut, Beirut 1107 2020, Lebanon
}

Received 9 May 2005; revised 4 July 2005; accepted 7 July 2005

\begin{abstract}
HLA alleles have been associated with psoriasis. Toxin-producing strains of Staphylococcus aureus behave as superantigens, and if present in patients, might play a role in the exacerbation of psoriatic lesions by activating certain V-beta (V $\beta$ ) T-lymphocyte subsets. Allele frequencies in 22 patients and 22 controls (alleles determined by DNA/SSP typing) were used to calculate a relative risk of 4.7 $(P<.05)$ for HLA-Cw6. S aureus was isolated from the throat of 11 patients. Enterotoxins A and C were detected by agglutination in the culture filtrate of one isolate. The enterotoxin A and/or C genes were detected by PCR in 9 isolates, and transcripts were detected by RT-PCR in 7 of them. None of the isolates from controls harbored enterotoxin genes. V $\beta$ expansions were detected by RT-PCR in all 22 patients. Low or no V $\beta$ expansions were obtained in controls. The association of HLA-Cw6 with psoriasis in Lebanese concurs with that reported for other ethnic groups. Toxin-producing isolates that colonize patients might play a role in the exacerbation of psoriatic lesions.
\end{abstract}

\section{INTRODUCTION}

Psoriasis is a common, chronic, inflammatory disorder of the skin with a marked immunological basis. It is characterized by the involvement of activated $\mathrm{T}$ cells, macrophages, Langerhans cells, and keratinocytes $[1,2]$.

The etiological aspects of psoriasis remain to be elucidated; however it is thought that the interaction of environmental and genetic factors contributes to the pathogenesis of the disease $[3,4,5]$.

With respect to environmental factors, streptococcal and staphylococcal infections are among the most common triggering factors that initiate and exacerbate the disease. These microorganisms produce a group of toxins that behave as superantigens [6]. Superantigens differ from conventional antigens in that they do not un-

Correspondence and reprint requests to Alexander M. Abdelnoor, Department of Microbiology and Immunology, Faculty of Medicine, American University of Beirut, Beirut 1107 2020, Lebanon, E-mail: aanoor@aub.edu.lb

This is an open access article distributed under the Creative Commons Attribution License which permits unrestricted use, distribution, and reproduction in any medium, provided the original work is properly cited. dergo processing. Rather, they bind from one side to the HLA class II molecule expressed on antigen presenting cells (APC) to a site outside the cleft, and from the other side to the lateral surface of the $\mathrm{V}$-beta $(\mathrm{V} \beta)$ region of the $\mathrm{T}$-cell antigen receptor (TCR). In doing so, they bypass the requirements for processing, presenting, and costimulatory molecules $[6,7,8,9]$. Superantigens can activate a relatively large population of $\mathrm{T}$ cells that bear particular $\mathrm{V} \beta$ elements, and result in an outpouring of cytokines that promote an immunological response $[8,9]$.

Staphylococcal enterotoxins are superantigens that seem to play a role in the pathogenesis of several immunologically-mediated diseases, such as psoriasis [10, $11]$.

On the other hand, genetic predisposing factors include the genes that encode HLA molecules. A number of HLA alleles have been associated with psoriasis. These include HLA-B13, B17, B39, B57, Cw6, Cw7, DR4, and DR7 [12].

The aims of this study were (1) to determine an HLA allele-psoriasis association in Lebanese patients, (2) to isolate and identify Staphylococcus aureus and Streptococcus sp from the throat of patients with psoriasis and controls, (3) to determine if there is clonal expansion of certain $\mathrm{V} \beta$ T-lymphocyte subsets $(\mathrm{V} \beta 2, \mathrm{~V} \beta 5.1, \mathrm{~V} \beta 8$, $\mathrm{V} \beta 12$, and $\mathrm{V} \beta 14$ ) in patients and controls, and (4) to 
determine whether the $S$ aureus isolates were enterotoxin (superantigen)-producing strains.

\section{METHODS}

\section{Subjects}

Twenty-two psoriatic patients (10 guttate, 9 vulgaris, and 3 pustular) included in this study were referred from the Dermatology Out-Patient Department, American University Of Beirut, Medical Center. Twenty-two healthy volunteers who had no known history of psoriasis served as controls.

\section{Blood specimens}

Blood was collected in citrated tubes. Following centrifugation, the buffy coat was aspirated and used for the determination of HLA class I and II alleles and V $\beta$ subset expansion.

\section{Throat cultures}

Throat swabs were collected from the 22 patients and controls, and cultured aerobically on sheep-blood agar plates (S-BAP). Suspected Staphylococci colonies were cultured in trypticase soy broth and tested for coagulase production, which is characteristic of $S$ aureus.

\section{Determination of HLA alleles, relative risks, odds ratios, and $P$ values}

A, B, C, DR, and DQ alleles and their frequencies were determined in psoriasis patients and controls. DNA was extracted from the buffy coat using GFX Genomic Blood DNA Purification kit (Amersham Pharmacia Biotech, Upsalla, Sweden), followed by amplification of alleles by PCR, utilizing the Micro SSP HLA DNA Typing Trays (One Lambda, Inc, Canoga Park, Calif).

MHC profiles were determined for all psoriasis patients, and controls. The relative risks, odds ratios, and $P$-values were calculated for each allele using the software package Stat Calc EpiInfo version 6.0 (Center For Disease Control, and Prevention, 1994).

\section{Determination of T-cell $\mathrm{V} \beta$ subset expansion by $R T-P C R$}

Clonal expansion of V $\beta$ T-lymphocyte subsets was determined in psoriasis patients, and controls. RNA was extracted from buffy coat using trizol reagent (total RNA isolation reagent is a monophasic solution of phenol and guanidine isothiocyanate provided by Life Technologies Inc, Gaithersburg, Md) and RT-PCR was performed on RNA extracts using the Ready-To-Go You-Prime FirstStrand Beads (Amersham Pharmacia Biotech, Upsalla, Sweden). The RNA sample (900 ng) and the control mix beads (rabbit globulin mRNA buffer and 8 pmol each of $5^{\prime}$-specific globulin primer; $5^{\prime}$-d ACA CTT CTG GTC CAG TCC GAC TGA G-3' and $3^{\prime}$ - specific primer; $5^{\prime}$-d GCC ACT CAC TCA GAC TTT ATT CAA A- $3^{\prime}$ ) were each made up to $23 \mu \mathrm{L}$ with DEPC-treated water, in RNase-free microcentrifuge tubes. The tubes were then heated at $65^{\circ} \mathrm{C}$ in a thermocycler for 10 minutes and immediately chilled on ice for 2 minutes. The RNA solution and the control mixed solution were transferred to the tubes of First-Strand Reaction Mix Beads without mixing. $0.5 \mu \mathrm{g}$ of oligo(dT) and DEPC-treated water were added to reach a final volume of $33 \mu \mathrm{L}$. Tubes were incubated at room temperature for one minute then at $37^{\circ} \mathrm{C}$ for 60 minutes. The synthesized cDNA was subjected to PCR using the following previously published primers [13].

(i) Vß2: 5' -TCATCAACCATGCAAGCCTGACCT-3'.

(ii) V $\beta 5.1: 5^{\prime}$-ATACTTCAGTGAGACACAGAGAAAC$3^{\prime}$.

(iii) V $\beta 8: 5^{\prime}$-ATTTACTTTAACAACAACGTTCCG-3' .

(iv) V $\beta 12: 5^{\prime}$-GGGGTCGACAAAGGAGAAGTCTCAG-

AT- $3^{\prime}$

(v) V $\beta 14:$ 5'-GTCTCTCGAAAAGAGAAGAGGAAT$3^{\prime}$.

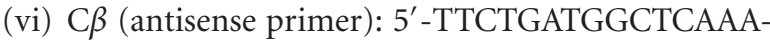
$\mathrm{CAC}-3^{\prime}$.

\section{Serological detection of staphylococcal enterotoxins $A, B, C$, and $D$}

Detection of enterotoxins in culture filtrates obtained from growing $S$ aureus isolates on trypticase soy agar (Difco, Detroit, Mich) was done using the staphylococcal enterotoxin-Reverse Passive Latex Agglutination (SETRPLA) kit according to the method described by the manufacturer (Oxoid Limited, Basing Stoke Hampshire, England).

\section{Detection of staphylococcal enterotoxins $A, B, C$, and $D$ genes by the polymerase chain reaction}

PCR was performed for the detection of staphylococcal enterotoxins A, B, C, and D genes on all $S$ aureus isolates from patients and controls. The primers for the four enterotoxin genes were selected from their nucleotide sequences (14-17). The sense and antisense primers used for each of the enterotoxins were as follows.

(i) Enterotoxin $\mathrm{A}$

(a) Sense: $5^{\prime}$-GCA GGG AAC AGC TTT AGG CAA TCT T-3'.

(b) Antisense: 5' - GAT TAA TCC CCT CTG AAC CTT CCC A-3'.

(ii) Enterotoxin B

(a) Sense: $5^{\prime}$-CAC CCA ACG TTT TAG CAG AGA GTC A-3'.

(b) Antisense: 5'-CAG GTA CTC TAT AAG TGC CTG CCT T-3'. 
TABLE 1. Toxin production by Staphylococcus aureus isolates, and Cw6 allele and V $\beta$ expansions in patients with psoriasis.

\begin{tabular}{|c|c|c|c|c|c|c|}
\hline \multirow[b]{2}{*}{ Patient number } & \multicolumn{3}{|c|}{$\begin{array}{l}\text { Staphylococcus aureus isolated; } \\
\text { toxin production }\end{array}$} & \multicolumn{3}{|c|}{ Patient } \\
\hline & Serology & Gene & Transcript & Type of psoriasis & $\mathrm{V} \beta$ expansion & Cw6 \\
\hline 1 & $-\mathrm{ve}$ & $\mathrm{C}$ & $-\mathrm{ve}$ & Vulgaris & $2,5.1,8$ & - ve \\
\hline 2 & - ve & $\mathrm{A}$ & $-\mathrm{ve}$ & Vulgaris & $2,5.1,8$ & + ve \\
\hline 3 & - ve & A & + ve & Pustular & $2,5.1,8$ & - ve \\
\hline 4 & $-\mathrm{ve}$ & $\mathrm{C}$ & $-\mathrm{ve}$ & Vulgaris & $\begin{array}{c}2,5.1,8 \\
12,14\end{array}$ & + ve \\
\hline 5 & $-\mathrm{ve}$ & $\mathrm{C}$ & + ve & Vulgaris & $2,5.1,8$ & $+\mathrm{ve}$ \\
\hline 6 & $-\mathrm{ve}$ & $-\mathrm{ve}$ & $-\mathrm{ve}$ & Guttate & $\begin{array}{c}2,5.1,8 \\
12,14\end{array}$ & + ve \\
\hline 7 & $\mathrm{~A}, \mathrm{C}$ & $A, C$ & $+\mathrm{ve}$ & Vulgaris & $\begin{array}{c}2,5.1,8 \\
12,14\end{array}$ & + ve \\
\hline 8 & $-\mathrm{ve}$ & $-\mathrm{ve}$ & $-\mathrm{ve}$ & Guttate & $\begin{array}{c}2,5.1,8 \\
12,14\end{array}$ & - ve \\
\hline 9 & - ve & A & $+\mathrm{ve}$ & Vulgaris & $\begin{array}{c}2,5.1,8 \\
12,14\end{array}$ & + ve \\
\hline 10 & $-\mathrm{ve}$ & $\mathrm{A}, \mathrm{C}$ & $+\mathrm{ve}$ & Vulgaris & $\begin{array}{c}2,5.1,8 \\
12,14\end{array}$ & + ve \\
\hline 11 & $-\mathrm{ve}$ & A & - ve & Guttate & $2,5.1,8$ & $+\mathrm{ve}$ \\
\hline
\end{tabular}

(iii) Enterotoxin C

(a) Sense: 5' - CAA CTG AGT TTA CTG GTA CGA TGG GT-3'.

(b) Antisense: 5' - CTG GTG CAG GCA TCA TAT CAT ACC-3'.

(iv) Enterotoxin D

(a) Sense: $5^{\prime}$-GGT ACT TCT AGG AAG GAC TAG CAT $\mathrm{GT}-3^{\prime}$.

(b) Antisense: 5'-GAG TGA CAC CTC CAT ATG TAC AAG- $3^{\prime}$.

Ten $\mu \mathrm{L}$ of extracted DNA and $90 \mu \mathrm{L}$ of amplification mix $\{30 \mathrm{pmol}$ of sense primer, $30 \mathrm{pmol}$ of antisense primer, $200 \mu \mathrm{M}$ of each deoxynucleoside triphosphate (AB gene, Surrey, UK), $10 \mu \mathrm{L}$ of PCR buffer (AB gene, Surrey, UK), and $0.5 \mu \mathrm{L}$ of Taq polymerase (AB gene, Surrey, UK) $\}$ were heated in a thermocycler at $94^{\circ} \mathrm{C}$ for 10 minutes followed by 35 cycles, each cycle included $94^{\circ} \mathrm{C}$ for 1 minute, $55^{\circ} \mathrm{C}$ for 1 minute, and $72^{\circ} \mathrm{C}$ for 1 minute. The cycles were terminated by a final extension step at $72^{\circ} \mathrm{C}$ for $10 \mathrm{~min}$ utes. The PCR amplicons obtained were detected by subjecting them to agarose gel electrophoresis and visualized using a UV transluminator and photographed with a Polaroid film type 667.

\section{Determination of staphylococcal enterotoxin transcripts by $R T-P C R$}

Extraction of RNA from $S$ aureus isolates that were enterotoxin gene-positive was performed utilizing the
TABLE 2. Relative risk, odd value, and $P$ value of MHC alleles in patients with psoriasis.

\begin{tabular}{lccc}
\hline Class I alleles & Relative risk & Odds ratio & $P$ values \\
\hline B13 & 3.65 & 4.1 & $<.05$ \\
B50 & 3.8 & 4.2 & $<.05$ \\
B57 & 2.2 & 2.3 & $<.05$ \\
Cw6 & 4.7 & 13.8 & $<.05$ \\
\hline
\end{tabular}

RNeasy Minikit (Qiagen, Hilden, Germany) and RT-PCR was performed on the RNA extracts using the Ready-ToGo You-Prime First-Strand Beads (Amersham Pharmacia Biotech). The manufacturers' procedure was followed in both cases. Amplification of cDNA was done using the above-mentioned primers and procedure.

\section{RESULTS}

The results are summarized in Table 1.

\section{Bacterial identification}

$S$ aureus was isolated from the throat of 11 of 22 psoriasis patients, and 2 of 22 apparently normal controls. Streptococci grew in throat cultures of all patients and controls but they were not grouped nor speciated.

\section{HLA profiles relative risk, odds ratio, $P$ values}

Alleles having a RR $>1$ and $P<.05$ are listed in Table 2. The highest RR was obtained for Cw6 $(\mathrm{RR}=4.7, P<$ $.05)$. 


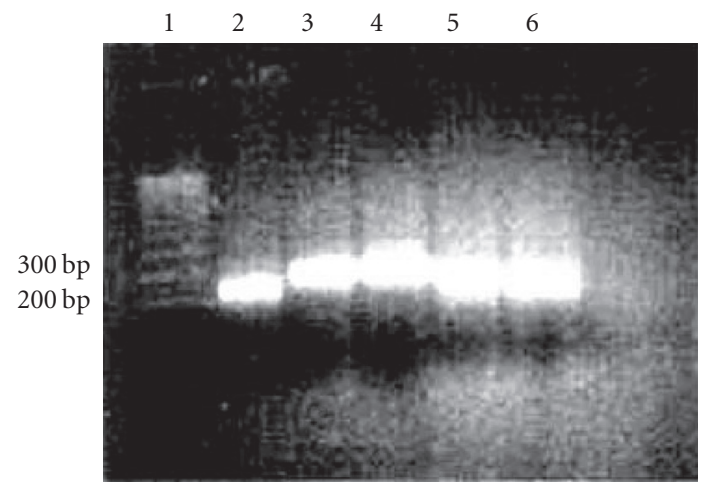

(a)

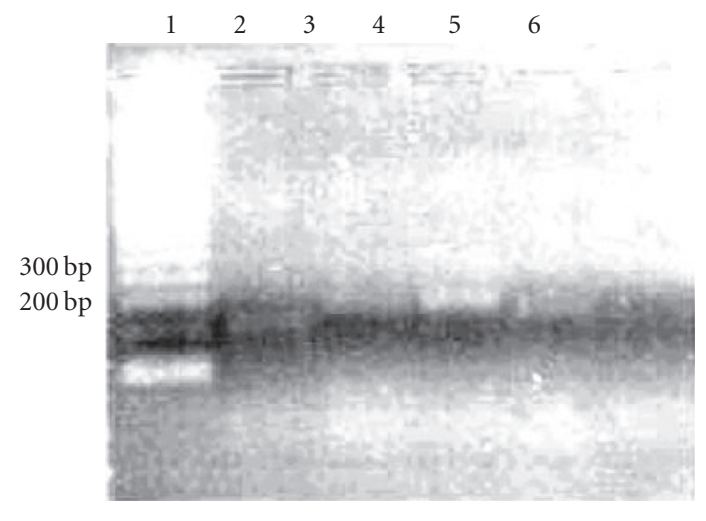

(b)

FIgURE 1. (a) RT-PCR amplification of the V $\beta$ subsets in psoriatic patients. Lane 1: 100-bp ladder, lane 2: $\mathrm{V} \beta 2$, lane 3: $\mathrm{V} \beta 5.1$, lane 4: V $\beta 8$, lane 5: V $\beta 12$, lane 6: V $\beta 14$, (b) RT-PCR amplification of the $\mathrm{V} \beta$ subsets in healthy individuals. Lane 1: 100-bp ladder, lane 2: $\mathrm{V} \beta 2$, lane 3: $\mathrm{V} \beta 5$.1, lane 4: $\mathrm{V} \beta 8$, lane 5: $\mathrm{V} \beta 12$, lane 6: $\mathrm{V} \beta 14$.

\section{$T$-cell $V \beta$ subset expansion- $R T$-PCR}

$\mathrm{V} \beta 2, \mathrm{~V} \beta 5.1$, and $\mathrm{V} \beta 8$ T-lymphocyte expansions were detected in high intensity in all 22 patients. In addition, $\mathrm{V} \beta 12$ and $\mathrm{V} \beta 14$ expansions were detected in 6 of $11 \mathrm{pa}-$ tients who harbored $S$ aureus. Low or no $\mathrm{V} \beta$ expansions were obtained in healthy controls. Representative $\mathrm{V} \beta$ region amplicons as observed by gel electrophoresis are shown in Figures 1a and $1 b$.

\section{Production of staphylococcal enterotoxins $A, B, C$, and $D$ in vitro}

Enterotoxins $\mathrm{A}$ and $\mathrm{C}$ were detected in the culture filtrate of one $S$ aureus isolate obtained from a psoriasis patient (titers of $1 / 64$ and 1/128, resp). Enterotoxins were not detected in culture filtrates of all other isolates.

\section{Detection of staphylococcal enterotoxin $A, B, C$, and $D$ genes}

Four of 11 isolates harbored only the enterotoxin $\mathrm{A}$ gene, 3 of 11 harbored only the enterotoxin $\mathrm{C}$ gene, and 2

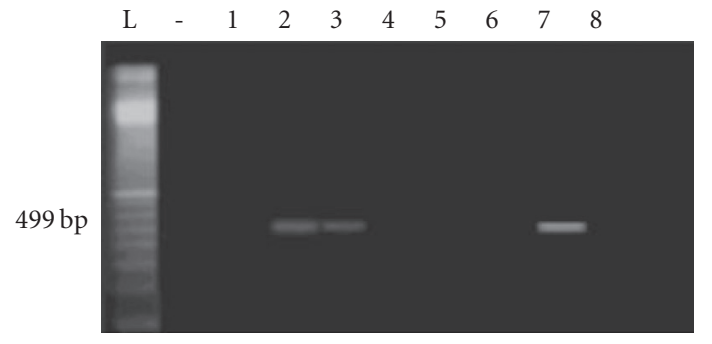

(a)

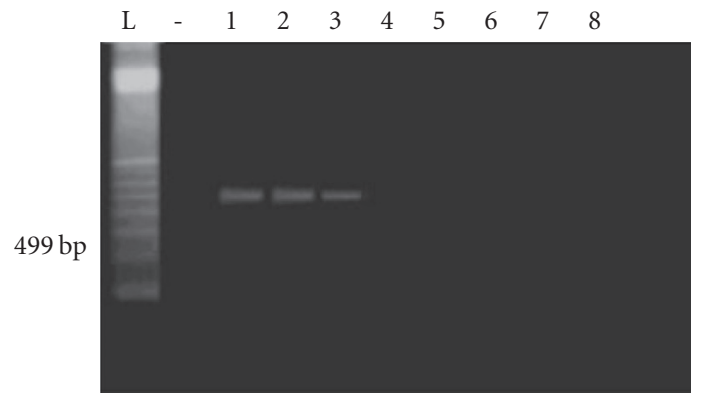

(b)

Figure 2. Enterotoxin A gene amplification: lanes L and (-): 100bp ladder and negative control. (a) Lanes 2-8: S aureus amplicons from psoriatic patients. (b) Lanes 1-3: $S$ aureus amplicons from psoriatic patients. Lanes 4 and 5: $S$ aureus amplicons from controls.

of 11 harbored both the enterotoxin $\mathrm{A}$ and $\mathrm{C}$ genes (total of 9 isolates having an $\mathrm{A}$ and/or $\mathrm{C}$ enterotoxin gene). None of the isolates from healthy controls harbored enterotoxin genes (Figures 2a, 2b, 3a, and 3b).

\section{Determination of staphylococcal enterotoxins transcripts}

Transcripts were detected in 4 of 6 isolates that harbored the enterotoxin A gene and 3 of 5 that harbored the enterotoxin $C$ gene (Figures 4 and 5).

\section{Relationship between toxin production by isolates and patients status}

All 5 isolates in which enterotoxin C transcript and/or gene were detected were obtained from patients with psoriasis vulgaris. Four of the isolates in which enterotoxin A transcript and/or gene were detected were obtained from patients with psoriasis vulgaris, 1 isolate was obtained from a patient with pustular psoriasis, and 1 from a patient with guttate psoriasis. Transcript and/or genepositive (A and/or $\mathrm{C}$ ) isolates were obtained from $4 \mathrm{pa}$ tients with psoriasis vulgaris who had V $\beta 12$ and $V \beta 14$ expansions.

\section{DISCUSSION}

By cross linking MHC class II molecules on macrophages to $\mathrm{T}$-cell receptors having the appropriate 


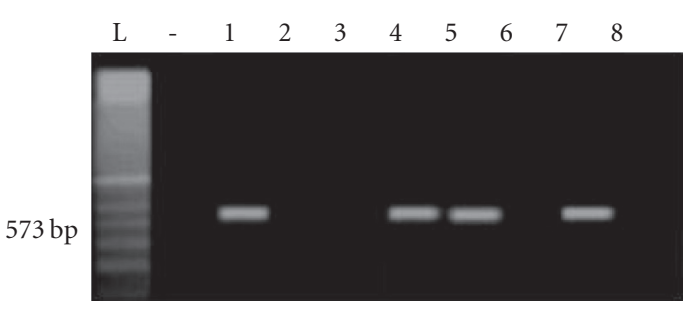

(a)

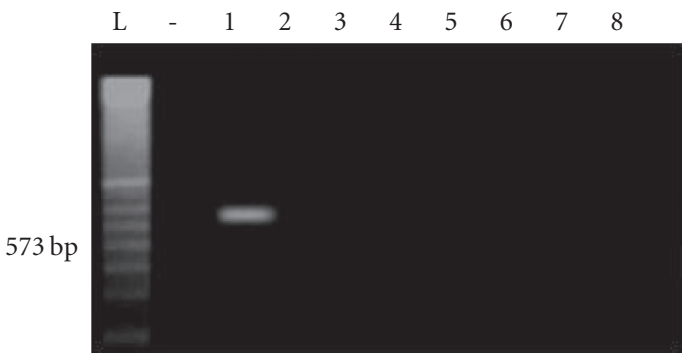

(b)

Figure 3. PCR done for the enterotoxin C gene on the $16 \mathrm{~S}$ aureus isolates. (a) Lane L: 100-bp ladder; lane (-): negative control; lanes 1-8: amplicons of $S$ aureus isolates from psoriatic patients. (b) Lane L: 100-bp ladder; lane(-): negative control; lanes 1-8: amplicons of $S$ aureus isolates from psoriatic patients in lane 1 and from control patients following in sequential order.

$\mathrm{V} \beta$ specificity, superantigens can cause excessive stimulation of both cell types. Up to $20 \%$ of all T-cells can be stimulated by any superantigen. The excessive production of cytokines by both macrophages and T-cells are thought to contribute to pathogenicity [14].

The fact that $\mathrm{V} \beta$ expansions were detected in all 22 patients supports the report of Leung et al [11, 15] who suggested a role of superantigens in the pathogenesis of psoriasis. Superantigens include some bacterial toxins such as those elaborated by certain strains of Streptococci and $S$ aureus. Davidson et al [16] reported on the relationship between Streptococcus and Staphylococcus colonization of the tonsils, and exacerbation of pustular and chronic plaque (vulgaris) lesions. $S s p$ was isolated from the throat of all patients. However, these isolates were not grouped or speciated. Moreover, their ability to elaborate toxins was not investigated. It could very well be that some of the $\mathrm{V} \beta$ expansions observed in patients might be due to toxins elaborated by the streptococcal isolates [17]. In this study we focused on toxin production by $S$ aureus isolated from patients. Serological detection of staphylococcal toxins in culture filtrates did not appear to be sensitive. Toxins A and $\mathrm{C}$ were detected in the culture filtrate of only one isolate. Hence, we resorted to the detection of genes that code for these toxins and their transcripts. Nine of 11 isolates were toxin A and /or C transcript and/or gene-positive. Staphylococcus toxin A causes $\mathrm{V} \beta 3$ and 11 expansions, both of which were not tested

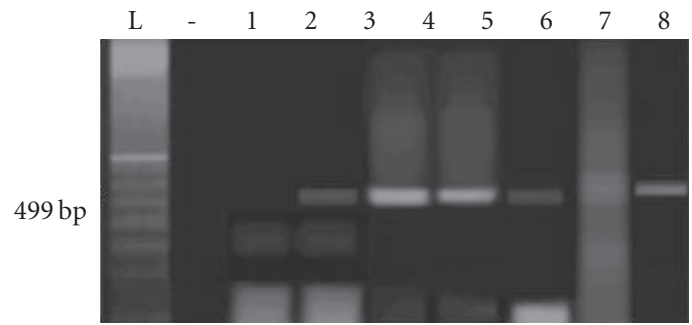

FIgURE 4. RT-PCR amplification of the enterotoxin A gene transcripts on the $6 S$ aureus isolates that tested positive for the corresponding gene by PCR. Lane L: 100-bp ladder; lane (-): negative control; lanes 1-7: RT-PCR amplicons of $S$ aureus isolates from psoriatic patients; lane 8: 550-bp positive control.

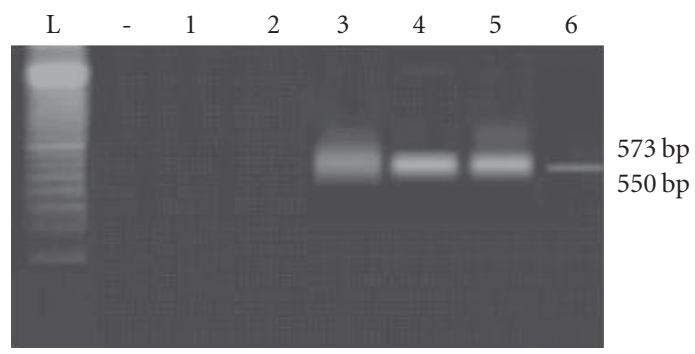

Figure 5. RT-PCR amplification of the enterotoxin C gene transcripts on the $5 \mathrm{~S}$ aureus isolates that tested positive for the corresponding gene by PCR. Lane L: 100-bp ladder; lane (-): negative control; lanes 1-5: RT-PCR amplicons of $S$ aureus isolates from psoriatic patients; lane 6: 550-000-bp positive control.

in this investigation. On the other hand, Staphylococcus $\mathrm{C}$ toxin causes $\mathrm{V} \beta 5.1,12$, and 14 expansions [14]. There was an expansion of $\mathrm{V} \beta 5.1$ in all patients and $\mathrm{V} \beta 12$ and $\mathrm{V} \beta 14$ in 2 patients whose $S$ aureus isolates where toxin $\mathrm{C}$ transcript and/or gene-positive. Four of the 9 genepositive isolates were transcript-negative. It might be that the transcripts were present in undetectable amounts, or transcription was inhibited in vitro. Most of the patients (7 of 11) from whom $S$ aureus was isolated had psoriasis vulgaris. However, it was not attempted to correlate the presence of toxin-producing strains with the type of psoriasis because of the small number of patients included.

Genetic predisposition studies related to psoriasis have been reported [12]. A number of HLA alleles have been associated with psoriasis. In concurrence with other ethnic group studies, Cw6, appeared to be associated with psoriasis in Lebanese patients. The calculated relative risk for the 22 patients was $4.7(P<.05)$. Moreover, 8 of 11 patients from whom $S$ aureus was isolated were Cw6 positive.

In conclusion, our data support, but does not confirm the role of superantigens such as toxins produced by $S s p$ and $S$ aureus in the exacerbation of psoriatic lesions in genetically predisposed individuals. The first part of this 
study focused on the $S$ aureus isolates as producers of superantigens. Work in progress deals with the streptococcal isolates as potential producers of superantigens in psoriatic patients.

\section{REFERENCES}

[1] Linden KG, Weinstein GD. Psoriasis: current perspectives with an emphasis on treatment. Am J Med. 1999;107(6):595-605.

[2] Stern RS. Psoriasis. Lancet. 1997;350(9074):349-353.

[3] Krueger GG, Duvic M. Epidemiology of psoriasis: clinical issues. J Invest Dermatol. 1994;102(6):14S$18 \mathrm{~S}$.

[4] Ortonne JP. Aetiology and pathogenesis of psoriasis. Br J Dermatol. 1996;135(suppl 49):1-5.

[5] Ortonne JP. Recent developments in the understanding of the pathogenesis of psoriasis. $\mathrm{Br} J$ Dermatol. 1999;140(suppl 54):1-7.

[6] Kotzin BL, Leung DYM, Kappler J, Marrack P. Superantigens and their potential role in human disease. Adv Immunol. 1993;54:99-166.

[7] Al-Daccak R, Mehindate K, Damdoumi F, et al. Staphylococcal enterotoxin D is a promiscuous superantigen offering multiple modes of interactions with the MHC class II receptors. J Immunol. 1998;160(1):225-232.

[8] Herman A, Kappler JW, Marrack P, Pullen AM. Superantigens: mechanism of T-cell stimulation and role in immune responses. Annu Rev Immunol. 1991;9:745-772.

[9] Marrack P, Kappler J. The staphylococcal enterotoxins and their relatives. Science. 1990;248(4956):705711.

[10] Balaban N, Rasooly A. Staphylococcal enterotoxins. Int J Food Microbiol. 2000;61(1):1-10.

[11] Leung DYM, Travers JB, Giorno R, et al. Evidence for a streptococcal superantigen-driven process in acute guttate psoriasis. J Clin Invest. 1995;96(5):21062112.

[12] Bos JD, De Rie MA. The pathogenesis of psoriasis: immunological facts and speculations. Immunol Today. 1999;20(1):40-46.

[13] Dunn DA, Gadenne A-S, Simha S, Lerner EA, Bigby M, Bleicher PA. T-cell receptor VB expression in normal human skin. Natl Acad Sci USA. 1993;90(4):1267-1271.

[14] Rosen F, Geha R. Case Studies in Immunology. A Clinical Companion. 4th ed. New York, NY:Garland Publishing; 2004.

[15] Leung DYM, Walsh P, Giorno R, Norris DA. A potential role for superantigens in the pathogenesis of psoriasis. J Invest Dermatol. 1993;100:225-228.

[16] Davison SC, Allen MH, Mallon E, Barker JN. Contrasting patterns of streptococcal superantigeninduced T-cell proliferation in guttate vs. chronic plaque psoriasis. Br J Dermatol. 2001;145(2):245251.
[17] Abe J, Forrester J, Nakahara T, Lafferty JA, Kotzin BL, Leung DYM. Selective stimulation of human T cells with streptococcal erythrogenic toxins A and B. J Immunol. 1991;146(11):3747-3750. 


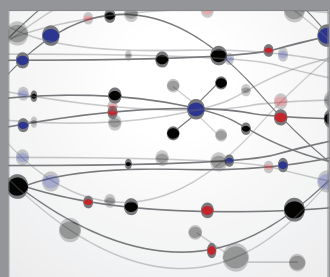

The Scientific World Journal
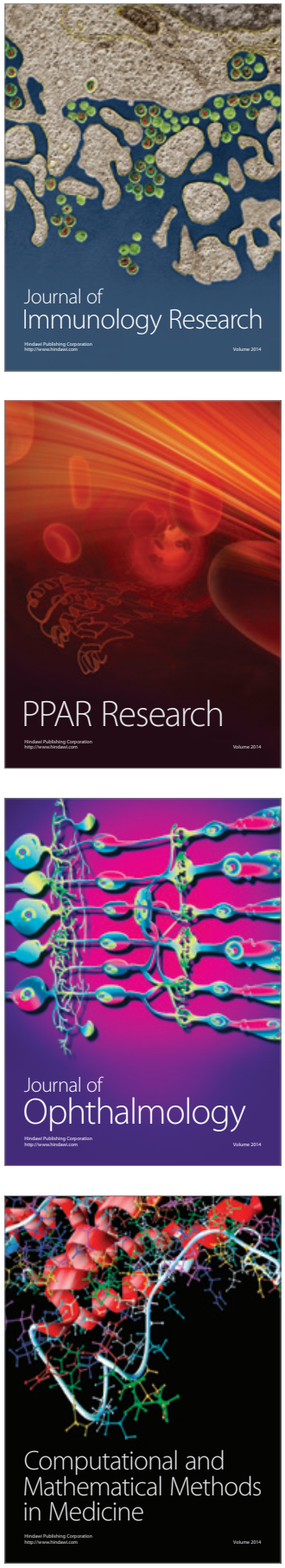

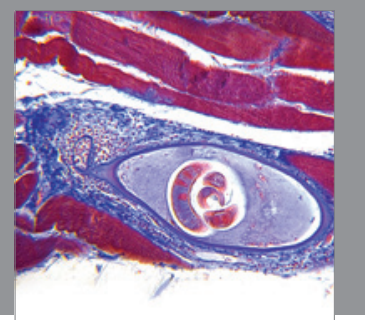

Gastroenterology

Research and Practice
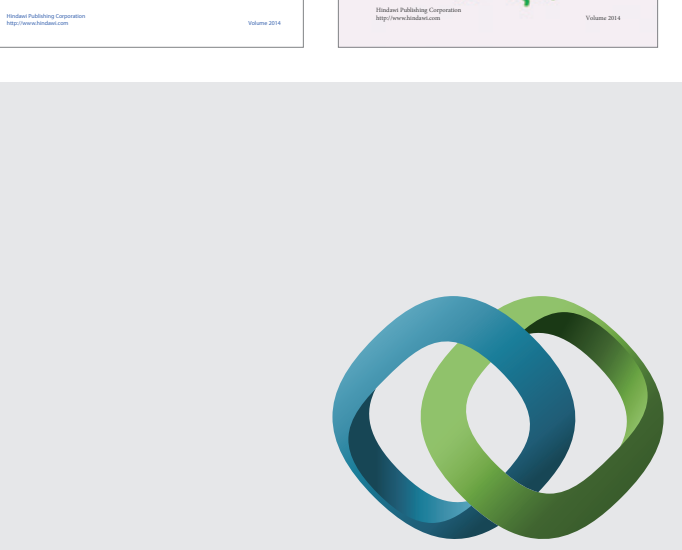

\section{Hindawi}

Submit your manuscripts at

http://www.hindawi.com
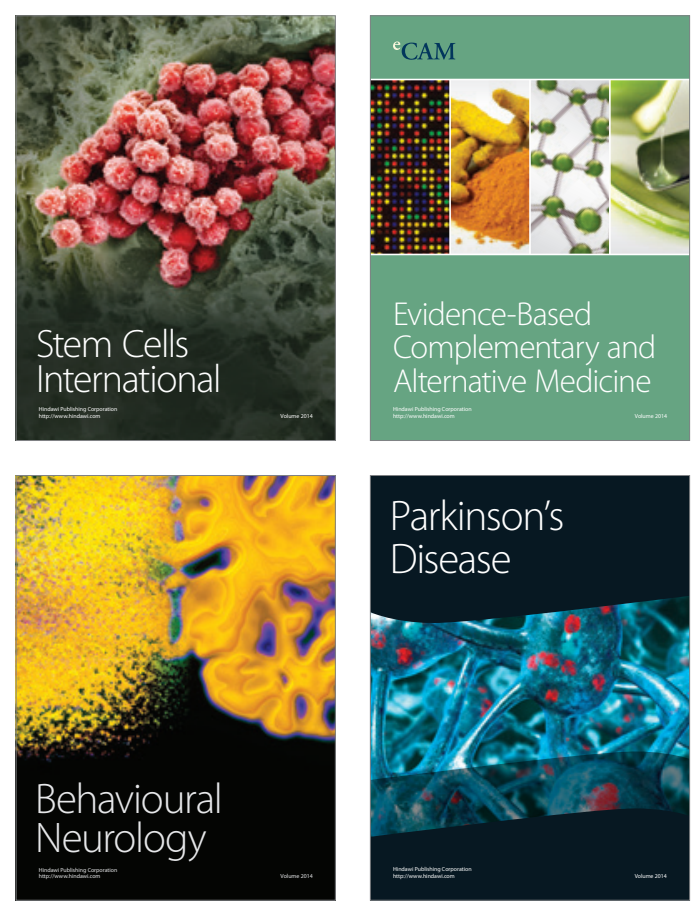

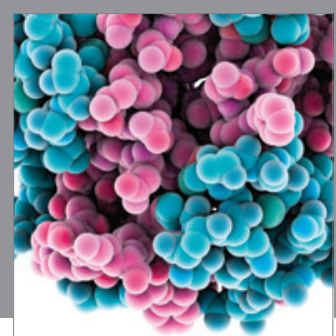

Journal of
Diabetes Research

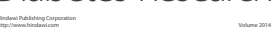

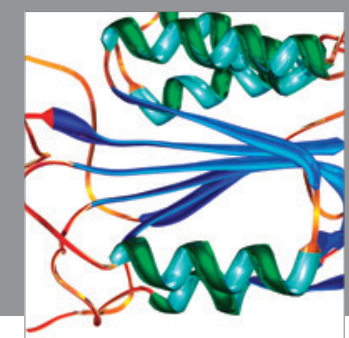

Disease Markers
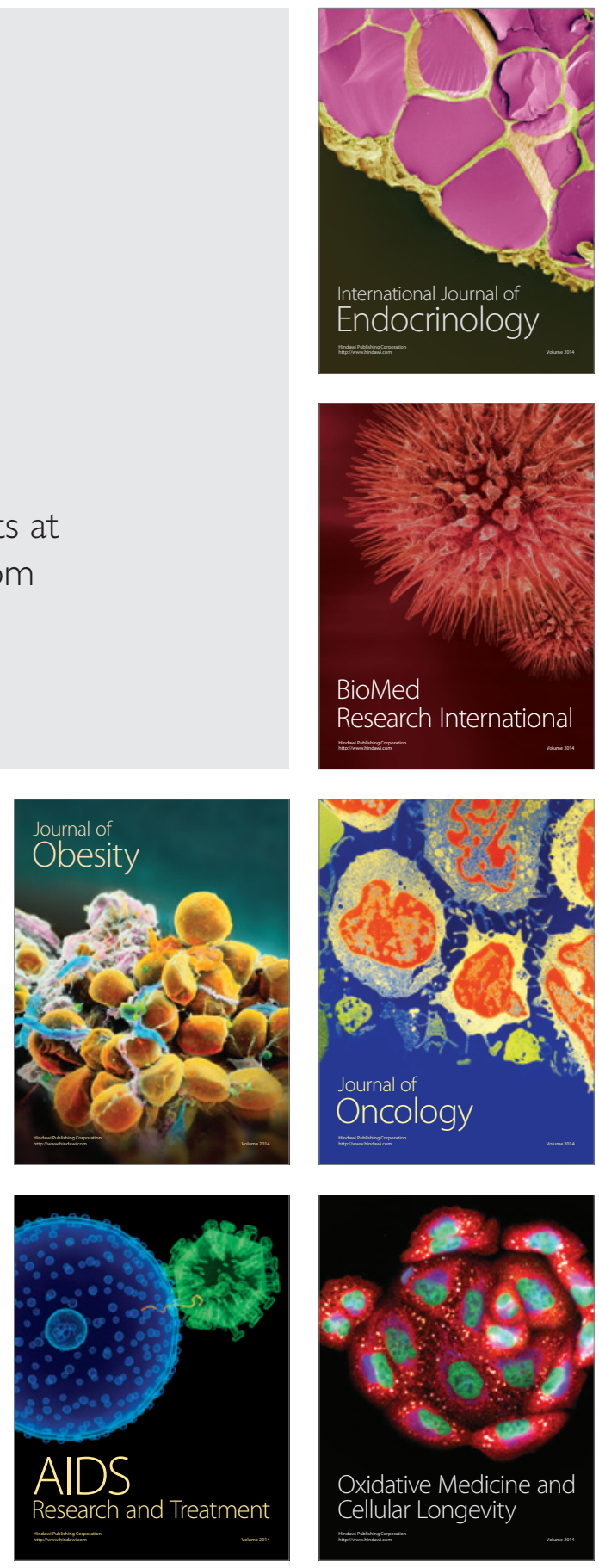